\title{
Experimental study of coal fracture dynamics under the influence of cyclic freezing-thawing using shear elastic waves
}

\author{
Petr V. Nikolenko ${ }^{1}$ (D) Svetlana A. Epshtein ${ }^{1}$ • Vladimir L. Shkuratnik ${ }^{1}$. \\ Polina S. Anufrenkova ${ }^{1}$
}

Received: 20 April 2020/Revised: 23 June 2020/Accepted: 10 July 2020/Published online: 10 August 2020

(C) The Author(s) 2020

\begin{abstract}
Cyclic freezing-thawing can lead to fracture development in coal, affecting its mechanical and consumer properties. To study crack formations in coal, an ultrasonic sounding method using shear polarized waves was proposed. Samples of three coal types (anthracite, lignite and hard coal) were tested. The research results show that, in contrast to the shear wave velocity, the shear wave amplitude is extremely sensitive to the formation of new cracks at the early stages of cyclic freezing-thawing. Tests also show an inverse correlation between coal compressive strength and its tendency to form cracks under temperature impacts; shear wave attenuation increases more sharply in high-rank coals after the first freezing cycle. Spectral analysis of the received signals also confirmed significant crack formation in anthracite after the first freeze-thaw cycle. The initial anisotropy was determined, and its decrease with an increase in the number of freezethaw cycles was shown. The data obtained forms an experimental basis for the development of new approaches to preserve coal consumer properties during storage and transportation under severe natural and climatic conditions.
\end{abstract}

Keywords Coal $\cdot$ Cyclic freezing-thawing $\cdot$ Ultrasonic $\cdot$ Shear wave $\cdot$ Fracture dynamics

\section{Introduction}

A significant number of coal deposits are located in the northern regions of Russian Federation (Pechora, Taimyr, Zyriansky coal basins) and far away from the major consumers. Coal, while being transported through various climatic zones and stored under various conditions, is often exposed to cyclically changing thermal impacts in positive and negative temperature ranges. Such impacts lead to changes in the mechanical and consumer properties of coal.

Since the middle of the last century, the scientific community has gained extensive experience in ascertaining the impact of temperature on the mechanical properties of rocks. Winkler (1968) found that phase transitions in pore

Petr V. Nikolenko

p.nikolenko@misis.ru

1 Scientific and Training Testing Laboratory of Physics and Chemistry of Coals, National University of Science and Technology MISiS, Moscow, Russian Federation 119049 moisture lead to increased pressure that can exceed the value of the rock mass pressure. Numerous studies (Finnie et al. 1979; Nicholson and Nicholson 2000; Lin et al. 2018) have shown that rocks of various genotypes exposed to negative temperatures lose their strength significantly, leading to their complete destruction. The generalization of experimental studies (Aoki et al. 1990; Dwivedi et al. 2000; Cai et al. 2014) indicates that the decrease in mechanical strength due to freezing is affected by the water content, the freezing rate and the duration of the freezing process, as well as the petrographic composition of the rocks.

In light of the aforementioned background, we consider the effect of cyclic freezing-thawing $(\mathrm{F}-\mathrm{T})$ operations on the properties of coals of various origins separately. Qualitatively, the disintegration mechanisms of coal and other rock types are very similar. However, the developed pore space, the crack systems of various orientations and the overall low initial strength make coal extremely sensitive to temperature changes. Therefore, in Cai et al. (2015, 2016) and Qin et al. (2017a, b), the effect of cyclic 
F-T with liquid nitrogen on the mechanical properties of coal was investigated. In these works, it was noted that an increase in the number of F-T cycles led to a nonlinear decrease in coal strength. In addition to strength, cyclic thermal shocks also affect other important characteristics of coal, such as methane permeability (Yu et al. 2012; Liu et al. 2015; Sun et al. 2018; Zhai et al. 2017), calorific value (Epshtein et al. 2019a, b) and propensity for spontaneous combustion (Deng et al. 2015). These results highlight the importance of studying the dynamics of coal disturbance under the influence of cyclically varying temperatures.

Traditional microscopy methods only allow for the evaluation of structural changes on sample surfaces (Epshtein et al. 2019a, b; Zhang et al. 2019). The same limitation applies to the study of coal mechanical properties by Nano indentation methods (Kossovich et al. 2016, 2018). The study of crack formation in the entire volume of a sample is possible using passive and active acoustic measurements in the ultrasonic frequency range.

Passive measurements involve the analysis of acoustic emissions in samples under the influence of mechanical or thermal test impacts. The most common method involves the cyclic F-T of coal samples and their subsequent uniaxial loading up to failure together with the registration of acoustic emission parameters (Qin et al. 2016, 2018). Other physical effects are sometimes used instead of uniaxial loading, such as rapid heating of a sample with simultaneous acoustic emission registration (Novikov et al. 2018). Such an approach makes it possible to estimate the crack development degree in a coal sample after thermal exposure. However, rapid heating leads to a change in the initial structure of the geo-material. The described method (being essentially destructive) does not allow multiple acoustic emission measurements to be performed on the same sample.

Active ultrasonic measurements avoid this problem. They suggest an analysis of changes in the kinematic informative parameters of ultrasonic signals in the coal samples subjected to cryothermal impacts. The most frequently used ultrasonic informative parameter is the propagation velocity of longitudinal waves $\left(V_{\mathrm{p}}\right)$. For example, Qin et al. $(2017 \mathrm{a}, \mathrm{b})$ showed that $V_{\mathrm{p}}$ decreases exponentially with increasing freezing time and the increasing number of F-T cycles of coal samples. $V_{\mathrm{p}}$ also depends on the moisture content. In this particular case, it should be noted that coal samples were exposed to extreme thermal shocks using liquid nitrogen. Therefore, crack formation is expected to be very intensive. In general, $V_{\mathrm{p}}$ is not overly sensitive to the formation of small cracks. A decrease in $V_{\mathrm{p}}$ occurs due to waves passing through the crack filler material, the speed of which is generally much lower. With small crack openings, the total path of the wave in the crack filler material will be insignificant when comparing with the general sounding base.

Unlike velocity, the amplitude of the longitudinal wave $\left(A_{\mathrm{p}}\right)$ can be more sensitive to the presence of cracks with small openings. The decrease in $A_{\mathrm{p}}$ is caused by the partial reflection of the wave at the "rock-filler material" boundary. In this case, the energy loss is affected not by the size of the crack opening but by the ratio of acoustic impedances at this boundary. Thus, during the F-T cycle of coal, the $A_{\mathrm{p}}$ parameter is sensitive not to the dynamics of crack openings but rather to the formation of new boundaries (cracks). Shkuratnik et al. (2016) showed that under the same conditions, $A_{\mathrm{p}}$ is much more sensitive to the formation of new cracks than $V_{\mathrm{p}}$ during the mechanical loading of coal samples. However, $A_{\mathrm{p}}$ is rarely used due to the difficulty of providing constant contact conditions at the "transducer-sample" boundary. Moreover, because they are not polarized, shear waves do not provide information on sample anisotropy.

More advanced sounding techniques involve the use of shear waves. These waves are known for high sensitivity to the presence of cracks. Shear waves depend on the shear modulus of elasticity $G$ and density $\rho$, both of which change significantly at crack boundaries. Shear waves are most commonly used to study rock masses on a large scale (Cha et al. 2009). Long wave propagation times make it relatively easy to separate longitudinal and shear waves during seismic exploration. Laboratory studies using highfrequency (hundreds of $\mathrm{kHz}$ ) shear waves are technically more sophisticated due to the emission and reception complexities of such waves. The separation of recorded $\mathrm{P}$ and $\mathrm{S}$ waves is also not an easy task. However, the use of shear waves can provide additional information on the formation of small-opening cracks in coal samples. The aim of this study is to use nontraditional highly sensitive ultrasonic sounding techniques to assess damage development in different coal types under low-magnitude cyclic thermal impacts. Using the velocities $\left(V_{\mathrm{s}}\right)$ and amplitudes $\left(A_{\mathrm{s}}\right)$ of shear waves (as well as their spectra) will provide information on crack formation in the typical temperature range conditions existing during coal mining and storage. This information can be used to predict mined coal degradation and develop recommendations for preserving the consumer properties of coal during its storage and transportation under severe natural and climatic conditions.

\section{Materials and methods}

\subsection{Laboratory setup}

The equipment used for studying the effect of cyclic cryothermal impacts on the acoustic characteristics of coal 
consists of a laboratory bench for ultrasonic testing (Fig. 1a, b) and a KTHV-150 multifunctional climatic chamber (Fig. 1c).

The laboratory setup consists of shear acoustic wave transducers (Gorbatsevich 1987) mounted on a frame so that the polarization planes of the emitted and received $\mathrm{S}$-waves coincide. The transducers allow emitting purely transverse, linear-polarized shear waves into a sample. It becomes possible via $\mathrm{P}$-wave to $\mathrm{S}$-wave conversion at the boundary of two acoustically different media located inside the transducer housing. This boundary is angled in such a way that the rays of transmitted $\mathrm{P}$-waves are beyond the critical angle so that only shear-waves propagate into the sample. Thus the transducers allow to maintain $A_{\mathrm{s}} / A_{\mathrm{p}}$ ratio greater than 3 in all received signals. The separation of the first arrivals of the longitudinal and transverse waves was performed according to the threshold principle. The transducers are broadband with a center frequency of $600 \mathrm{kHz}$. A sample orientation device is also provided on the frame, allowing the sample $360^{\circ}$ rotation around the vertical axis with a step of $1^{\circ}$. A signal from the pulse generator in the form of a meander with amplitude of up to $300 \mathrm{~V}$ is sent to the emitting transducer. The receiving transducer is connected to the input of an E20-10 analogto-digital converter with a sampling frequency of $5 \mathrm{MHz}$, which is connected to a personal computer. The recording length of the signal is 1024 samples (205 ms). The determination of $V_{\mathrm{s}}$ and $A_{\mathrm{s}}$ is performed in automated mode as a result of averaging the results of 50 consecutive measurements.

Special attention is paid to the mechanism of the shear wave energy transition at the "emitting transducer-coal" and "coal-receiving transducer" boundaries. Traditional ultrasonic P-wave measurements involve the use of water or various mineral lubricants as a coupling medium. Such media is not suitable for $\mathrm{S}$-wave transmission due to its low shear elasticity in the ultrasonic frequency range. The original technique (Gorbatsevich 2003) assumed the use of highly viscous solutions of noncrystallized sugar. This medium made it possible to successfully measure $V_{\mathrm{s}}$ and $A_{\mathrm{s}}$

a
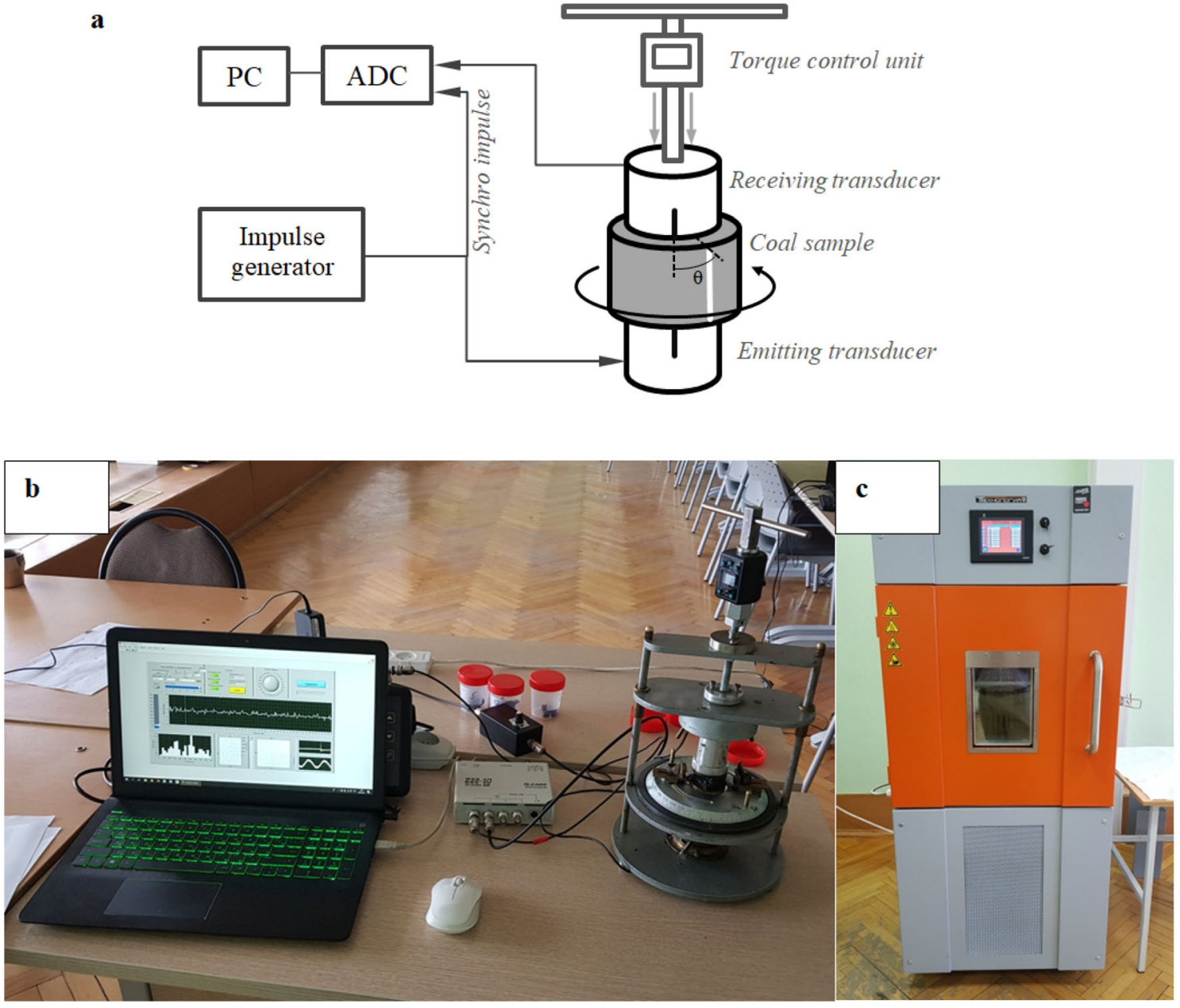

Fig. 1 Laboratory equipment: a, b ultrasonic testing setup; c KTHV-150 climatic chamber 
in rock samples. However, trial tests showed that the use of such a lubricant led to its penetration into pores and cracks on the coal surface, significantly affecting its acoustic characteristics. In addition, because this lubricant has a different coefficient of thermal expansion, it destroys the surface layer of the sample after freezing and thawing. Studies of the acoustic properties of coal under cyclic F-T conditions have shown that it is fundamentally important to completely abandon the use of liquid binders. This ensures a proper acoustic contact between the sample and the transducers. In this study, fine-grit abrasive paper glued to the acoustic transducer protectors was used to ensure acoustic contact. This technique led to a slight decrease in sensitivity, but it allowed us to maintain the constancy of the measurement conditions, regardless of the F-T cycle number (Shkuratnik et al. 2020). Additionally, to achieve repeatability of the acoustic contact during tests, the clamping force of the transducers was controlled using a digital torque control unit.

\subsection{Sample preparation}

The research involved three groups of coal samples taken from the Donetsk basin (anthracite, group A), Borodinsky (lignite, group L) and Apsatsky (hard coal, group H) deposits located in the Russian Federation. The sample parameters and group averaged coal characteristics are given in Table 1.
Coal samples were taken from coal seams outside the oxidation zone. Immediately after extraction from the reservoir, the samples were placed in a sealed container to prevent oxidation processes. Before testing, the samples were left for 1 day at room temperature to remove external moisture (conditioning).

Sample preparation consisted of dry grinding of the two opposing parallel surfaces, ensuring that the face area exceeded the footprint of the acoustic transducer. The height of all samples was $20 \mathrm{~mm}$. Side faces were left "as is". Thus, the sample preparation procedure was much less time-consuming than the preparation of standard cylindrical samples for mechanical strength tests.

\subsection{Experimental procedure}

A mark was applied to the surface of the prepared samples, indicating the initial position during ultrasonic sounding $\left(\theta=0^{\circ}\right)$. Before the cyclic thermal loading began, the values of $V_{\mathrm{s}}$ and $A_{\mathrm{s}}$ were experimentally determined for all samples with a step of $30^{\circ}$. Thus, an array of data on the primary state of coal was formed ( 0 cycle). The measurement results were presented in the form of polar diagrams of the informative parameter values at different angles. Then, the samples were placed in the KTHV-150 climatic chamber, where they were cyclically frozen-thawed at a temperature range from -40 to $+20{ }^{\circ} \mathrm{C}$ according to the program shown in Fig. 2. The humidity level of the ambient air remained constant at $30 \%$. As noted earlier

Table 1 Coal sample parameters

\begin{tabular}{|c|c|c|c|c|c|c|c|c|c|c|}
\hline \multirow[t]{2}{*}{ Group } & \multirow[t]{2}{*}{ Sample } & \multirow[t]{2}{*}{ Sample height (mm) } & \multicolumn{4}{|c|}{ Maceral composition (vol\%) } & \multicolumn{3}{|c|}{ Proximate analysis (mass\%) } & \multirow[t]{2}{*}{ Uniaxial strength (MPa) } \\
\hline & & & $\mathrm{Vt} / \mathrm{H}$ & $\mathrm{Sv}$ & I & $\mathrm{L}$ & $W^{\mathrm{a}}$ & $A^{\mathrm{d}}$ & $V^{\text {daf }}$ & \\
\hline \multirow[t]{5}{*}{ Anthracite (group A) } & A1 & 20.1 & 85 & 6 & 9 & 0 & 1.2 & 4 & 3.5 & 22 \\
\hline & A2 & 20.0 & & & & & & & & \\
\hline & A3 & 20.0 & & & & & & & & \\
\hline & A4 & 20.0 & & & & & & & & \\
\hline & A5 & 20.1 & & & & & & & & \\
\hline \multirow[t]{5}{*}{ Lignite (group L) } & L1 & 20.2 & 93 & - & 7 & 0 & 1.7 & 7 & 48 & 12 \\
\hline & $\mathrm{L} 2$ & 20.0 & & & & & & & & \\
\hline & L3 & 20.1 & & & & & & & & \\
\hline & L4 & 20.1 & & & & & & & & \\
\hline & L5 & 20.0 & & & & & & & & \\
\hline \multirow[t]{5}{*}{ Hard coal (group H) } & H1 & 20.0 & 71 & 13 & 16 & 0 & 0.6 & 9 & 19.8 & 15.2 \\
\hline & $\mathrm{H} 2$ & 20.1 & & & & & & & & \\
\hline & $\mathrm{H} 3$ & 20.1 & & & & & & & & \\
\hline & $\mathrm{H} 4$ & 20.0 & & & & & & & & \\
\hline & H5 & 20.2 & & & & & & & & \\
\hline
\end{tabular}

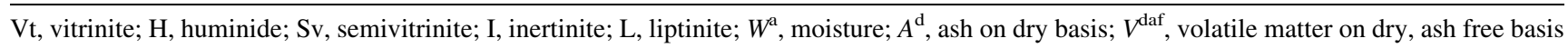




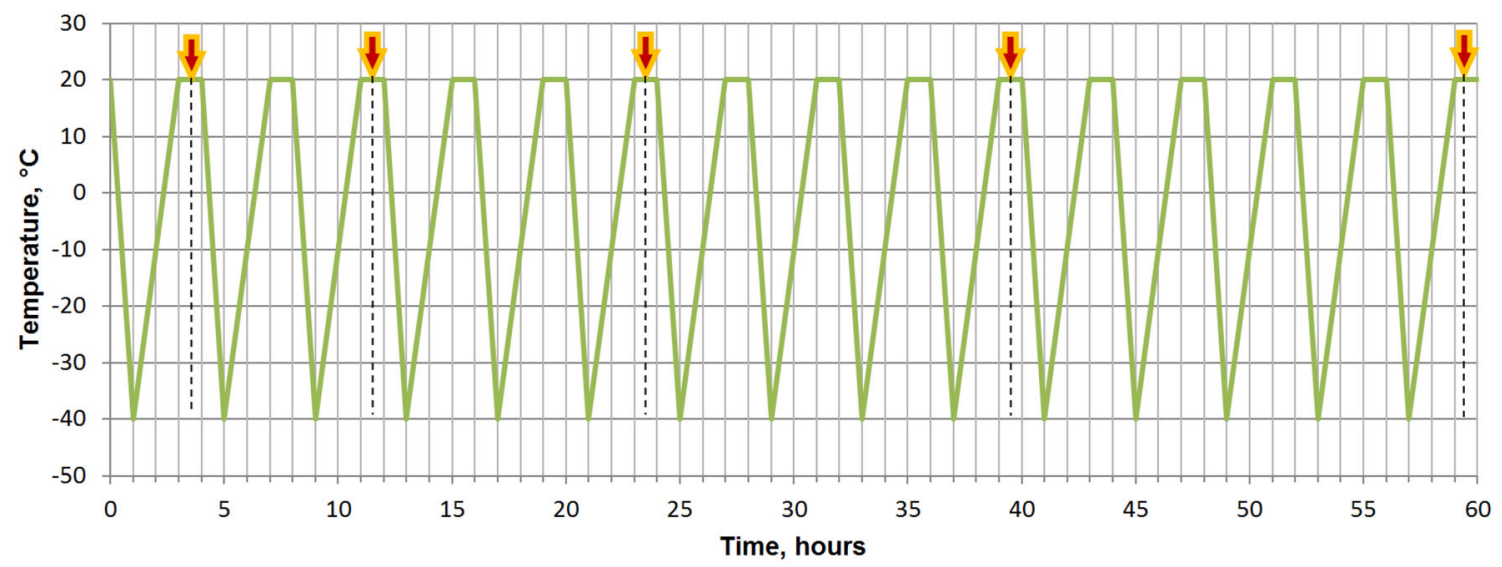

Fig. 2 Cyclic freeze-thaw paths (arrows indicate ultrasonic testing procedure)

(Qin et al. 2017a, b), the degradation of the mechanical properties of coal appears in a nonlinear fashion. More significant changes are observed after the first freeze-thaw cycles. In the present study, ultrasonic tests were taken at irregular steps to minimize the chances of sample damage. The total number of cycles was selected as follows. If significant changes in acoustic parameters were not observed during several measurements, then the experiment stopped. Therefore, ultrasonic tests were performed after $1,3,6,10$, and 15 cycles. Outside of the climatic chamber, coal samples were stored in airtight containers, guaranteeing the constant moisture content (humidity) of all samples.

\section{Results}

\subsection{The effect of cyclic freezing-thawing on the amplitudes and velocities of shear waves}

Arrays of $V_{\mathrm{s}}$ and $A_{\mathrm{s}}$ values were obtained for each coal sample, along with the angle of $\theta$ and numbers of $\mathrm{F}-\mathrm{T}$ cycles. These arrays were represented in the form of polar diagrams. Figure 3 shows the $V_{\mathrm{s}}$ measurement results for the coal samples of all three groups.

It can be seen from Fig. 3 that no significant $V_{\mathrm{s}}$ change is observed after $15 \mathrm{~F}-\mathrm{T}$ cycles. The $V_{\mathrm{s}}$ change for anthracite coal lies in the $16 \%$ range. For lignite and hard coal, $V_{\mathrm{s}}$ changes even less ( $9 \%$ and $14 \%$, respectively). Unlike $V_{\mathrm{s}}$, substantial changes in $A_{\mathrm{s}}$ can be observed in all coal types, as shown in Fig. 4.

From Fig. 4, a sharp change in $A_{\mathrm{s}}$ value can be seen for all coal types. This is most clearly visible on the anthracite sample, where $A_{\mathrm{s}}$ declines by $79 \%$ after $15 \mathrm{~F}-\mathrm{T}$ cycles (for the sounding direction $\theta=60^{\circ} / 240^{\circ}$ ). For hard coal, the decline in $A_{\mathrm{s}}$ lies in the $55 \%$ range (for $\theta=150^{\circ} / 330^{\circ}$ ). The smallest changes are observed in lignite samples, where $A_{\mathrm{s}}$ declines in the $33 \%$ range $\left(\theta=0^{\circ} / 180^{\circ}\right)$ after $6 \mathrm{~F}-\mathrm{T}$ cycles. All samples of the $\mathrm{L}$ group collapsed between the sixth and tenth cycles; therefore, only the measurement results after $0,1,3$, and 6 cycles are presented.

A significantly larger change in the value of $A_{\mathrm{s}}$ compared to $V_{\mathrm{s}}$ was observed in all studied samples of the three groups. The high sensitivity to new crack formation in a coal sample determines its further use as the main informative parameter.

Figure 4 shows that as the number of F-T cycles grows, the area bounded by the polar diagram drops. Such area can be calculated as

$S=\sum_{i=1}^{n} A_{\mathrm{s} i}$

where $A_{\mathrm{s} i}$ is the shear wave amplitude taken in a given direction and $n$ is the number of measurements taken $\left(n=13\right.$ with an angle step of $\left.30^{\circ}\right)$.

The decrease in $S$ value is caused by the influence of crack formation on the damping parameters of the shear waves. Thus, $S$ can indirectly indicate the overall number of cracks in the sample and the change dynamics in the F-T process. Diagrams of the averaged $S$ values for different coal types are presented in Fig. 5.

The results of the experiments also show that the initial anisotropy of acoustic properties is observed in all samples. This also changes as the number of $\mathrm{F}-\mathrm{T}$ cycles grows. Figure 6 shows the change in the anisotropy coefficient $K_{\mathrm{a}}$, calculated according to

$K_{\mathrm{a}}=\frac{A_{\mathrm{smax}}}{A_{\mathrm{smin}}}$,

where $A_{\text {smax }}$ and $A_{\text {smin }}$ are the maximum and minimum amplitudes of the shear wave, respectively. 

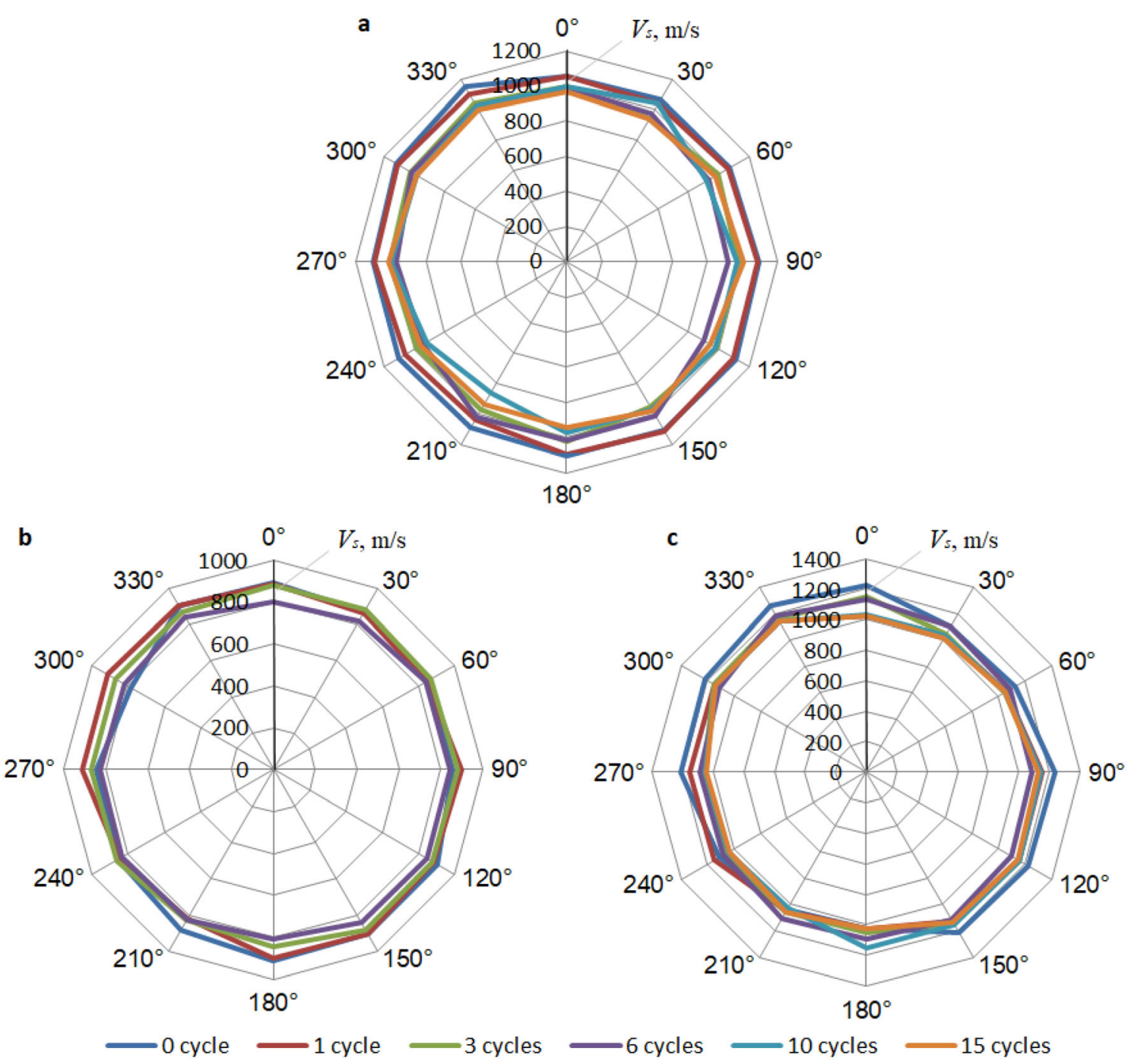

Fig. 3 Examples of S-wave velocity polar diagrams for anthracite samples (a), lignite samples (b) and hard coal samples (c)

\subsection{Spectral analysis}

As mentioned earlier, informative parameters such as the speed and amplitude of longitudinal waves (rarely shear waves) are most often used when utilizing ultrasonic methods to assess the damage degree of various materials. Additional information on the degree and nature of disturbances in the sample, especially on its dynamics, can be obtained by using the spectral analysis of the received signals (Shamina and Palenov 2000; Santos et al. 2010). More often, the values of the spectrum width $\Delta f$ and the frequency of the spectral maximum $f_{\max }$ are used as informative parameters. Thus, Remy observed a decrease in these parameters when approaching the rock sample collapse stage (Remy et al. 1994).

In the present work, the recorded signals were also subjected to spectral processing. The signals received along the direction of the main axis of anisotropy are of the greatest interest in this case. The spectral analysis consisted of signal spectrogram formation, where the numbers of $\mathrm{F}-$ $\mathrm{T}$ cycles were set along the horizontal axis, the frequencies of acoustic signals were set along the vertical axis, and amplitudes were coded by color. Spectrograms are obtained by sequentially placing the normalized spectra of signals subjected to fast Fourier transform. Examples of spectrograms for all three types of studied coals are presented in Fig. 7.

The relative change in the signal spectrum width is of particular interest when fractured media are being studied. This parameter is extremely sensitive to the extent and opening of cracks. The signal passing through the crack, which is an acoustically lowpass filter, undergoes significant changes. As a rule, such changes consist of the loss of the high-frequency spectral components and the general narrowing of the spectrum (Kundu 2019). To estimate the 

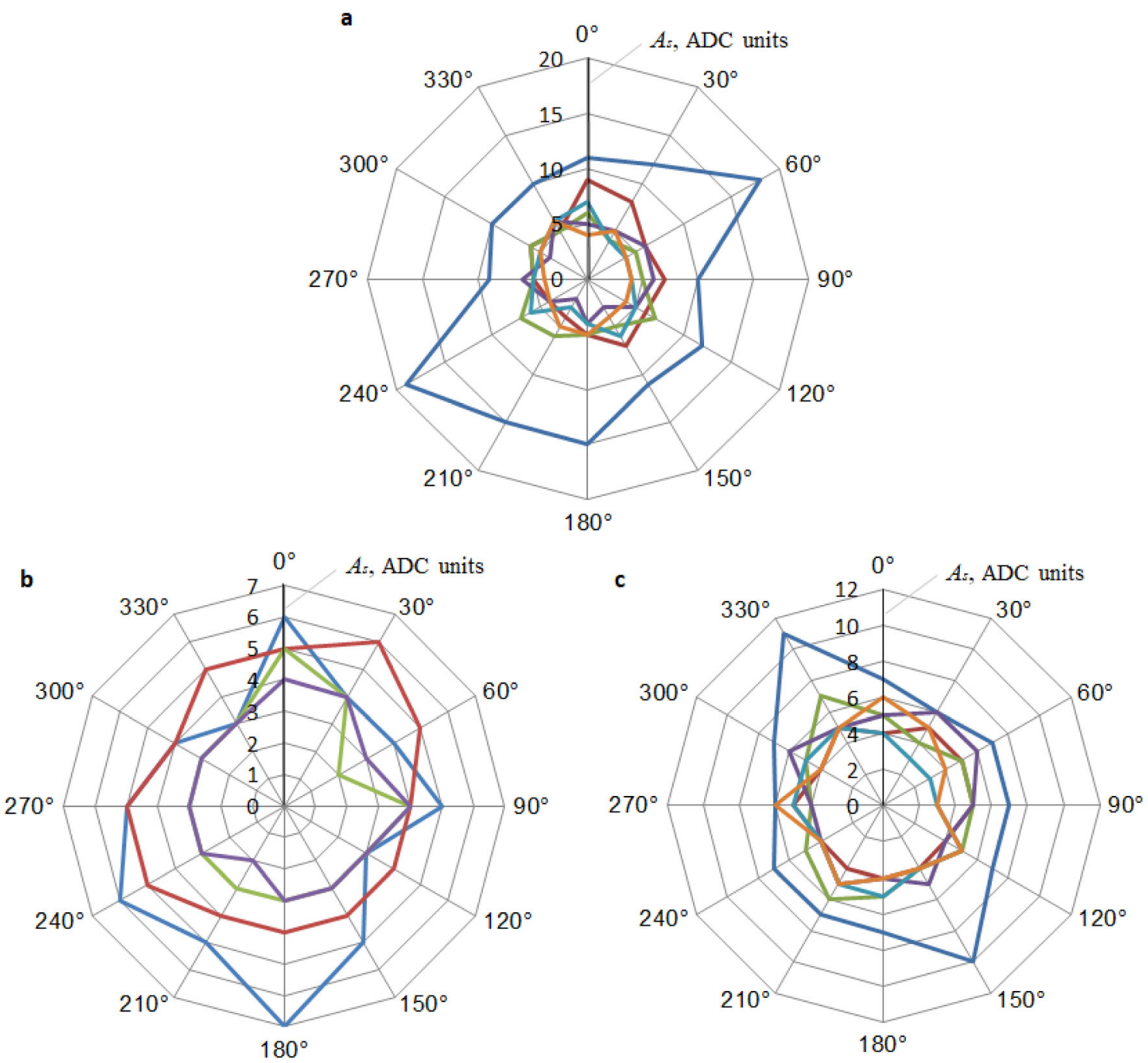

-0 cycle -1 cycle -3 cycles -6 cycles -10 cycles -15 cycles

Fig. 4 Examples of S-wave amplitude polar diagrams for anthracite samples (a), lignite samples (b) and hard coal samples (c)

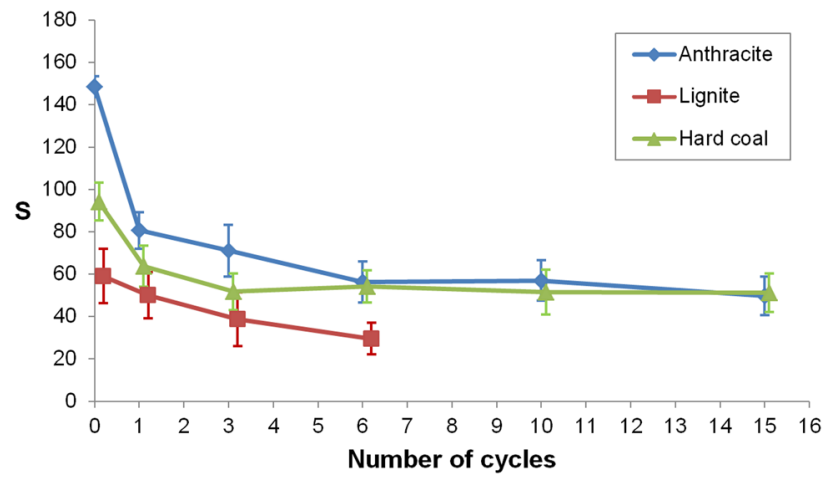

Fig. 5 Influence of F-T cycles on averaged $S$ parameter for different coal types (bars indicate standard deviation)

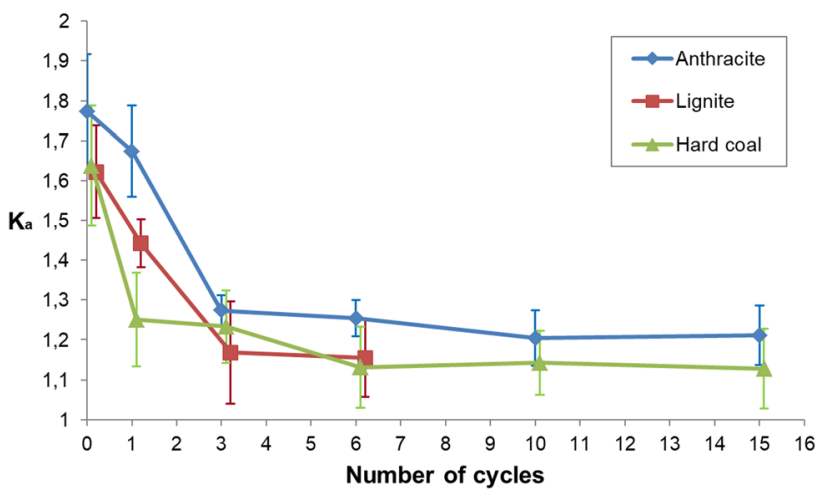

Fig. 6 Change in the averaged $K_{\mathrm{a}}$ with an increase in F-T cycle number (bars indicate standard deviation) 

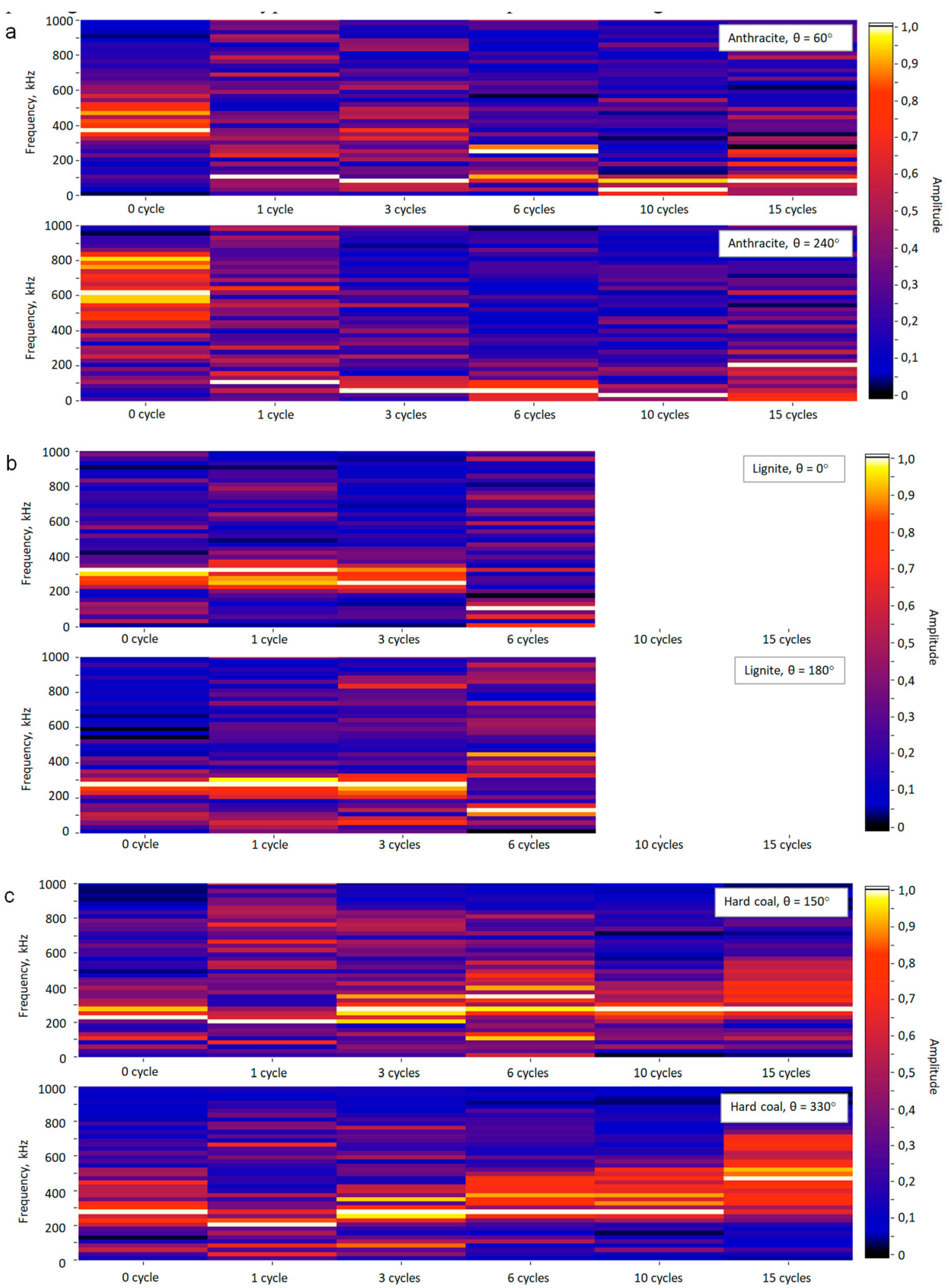

Fig. 7 An example of spectrograms obtained along the main axis of anisotropy in a anthracite sample; b lignite sample; $\mathbf{c}$ hard coal sample

relative change in the spectrum width, we use the correlation interval $\tau_{\mathrm{k}}$ calculated according to

$$
\tau_{\mathrm{k}}=\frac{1}{B(0)} \int_{0}^{\infty} B(\tau) \mathrm{d} \tau
$$


where $B(0)$ is the autocorrelation function of the received signal taken at $\tau=0$ and $B(\tau)$ is the autocorrelation function of the received signal.

The $\tau_{\mathrm{k}}$ parameter shows the time interval at which the signal remains correlated with itself for the noise signal $\tau_{\mathrm{k}} \rightarrow 0$ and for the deterministic signal $\tau_{\mathrm{k}} \rightarrow \infty$. Thus, $\tau_{\mathrm{k}}$ is inversely proportional to the width of the signal spectrum. The $\tau_{\mathrm{k}}$ calculation results for signals obtained in the direction of the main axis of anisotropy for all three sample groups are presented in Fig. 8.

\section{Discussion}

Comparative studies (Pan et al. 2013) have indicated that anthracite has high strength and uniformity, as well as a low level of initial disturbance. Mechanical characteristics

a

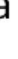

$\tau_{\mathrm{k}, \mathrm{mks}}$

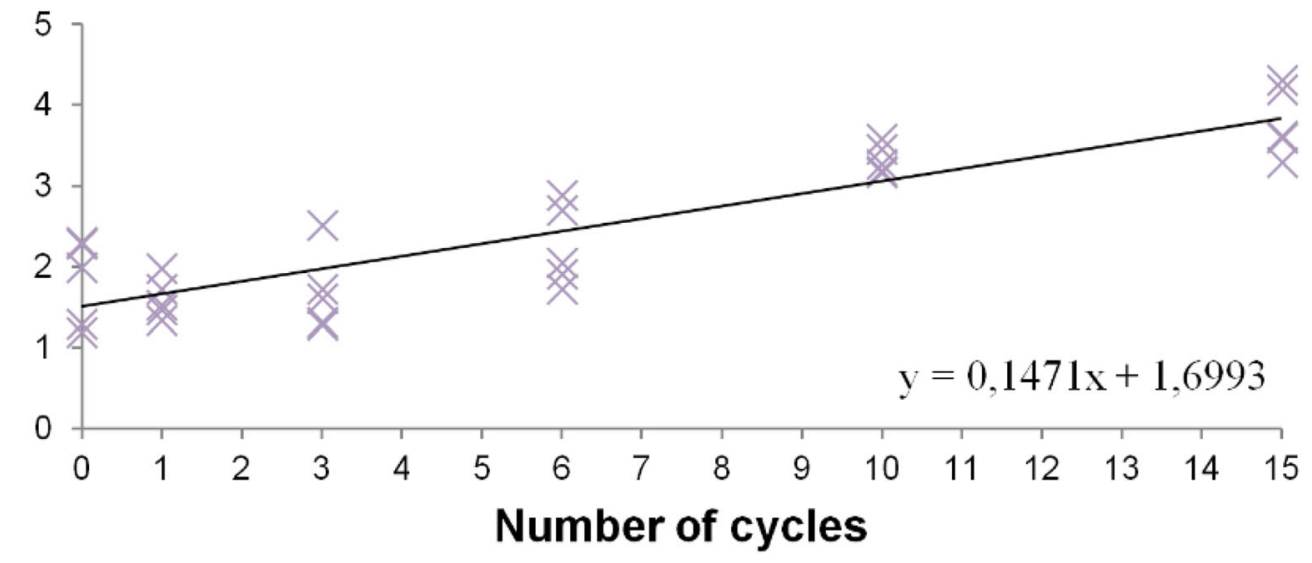

b

$\tau$, mks
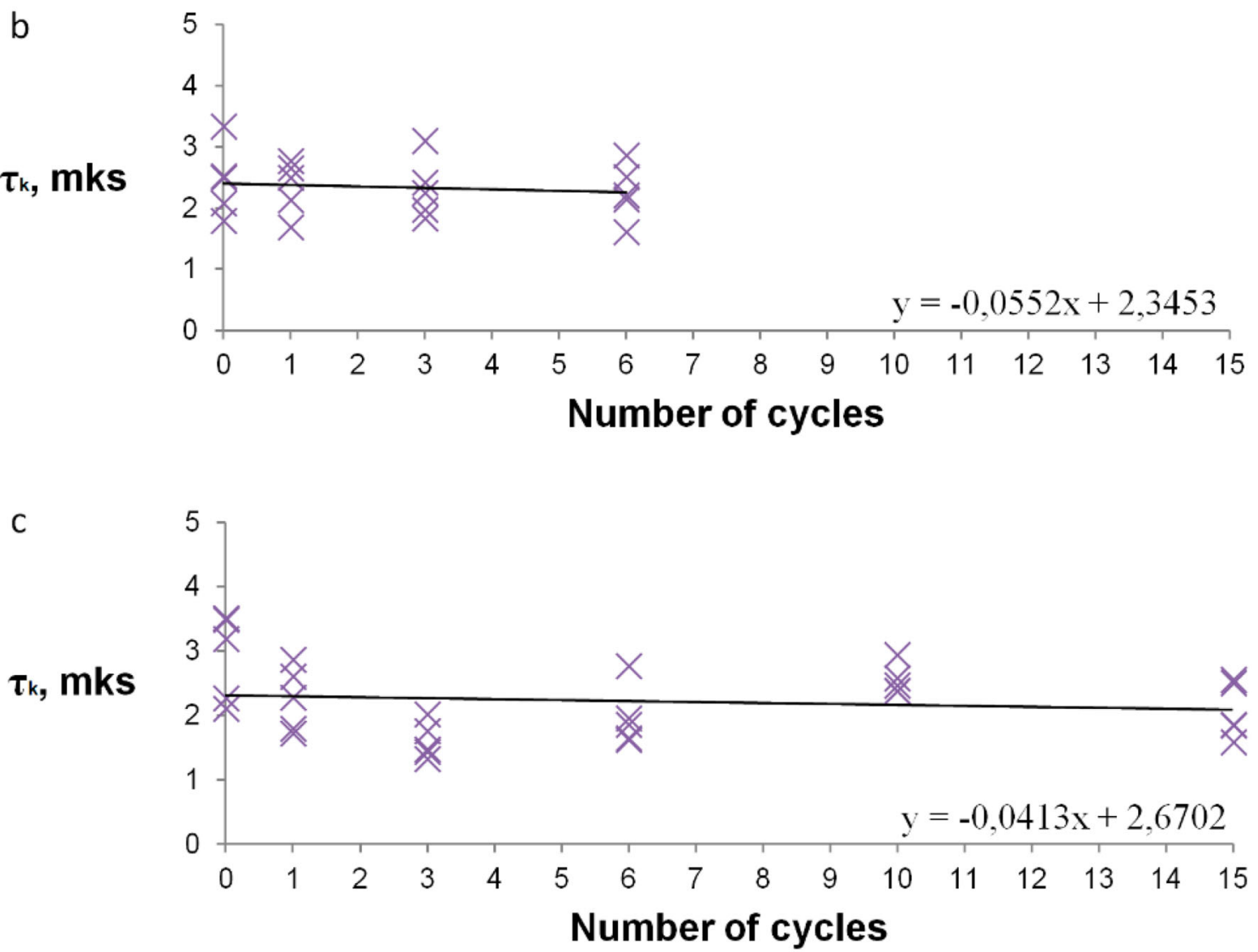

Fig. 8 Dependence of $\tau_{\mathrm{k}}$ obtained along the main axis of anisotropy on the number of F-T cycles for a anthracite samples; $\mathbf{b}$ lignite samples; c hard coal samples 
are reduced with the transition to hard coal. Lignite most often has the lowest strength and a high initial disturbance, which often results in the impossibility of manufacturing standard samples for mechanical tests. These results correspond well with the uniaxial strength of the coals used in the present study. Additionally, a positive correlation between the $S$ value and the uniaxial compressive strength of different coal types at the \#0 F-T cycle is observed. In more uniform and stronger coals, shear waves experience less attenuation due to the low number of initial cracks. As the number of F-T cycles increases, $A_{\mathrm{s}}$ values decline in a nonlinear fashion. From Figs. 4 and 5, it can be seen that the greatest change in $A_{\mathrm{s}}$ in anthracite samples occurs after the first F-T cycle. The difference between $S$ values at zero and after the first F-T cycle exceeds $100 \%$. Further decline is much smoother. By cycle \#15, the $S$ value is reduced by an additional $25 \%$. A similar pattern is observed in hard coal samples. After the first cycle, there is a $32 \%$ decrease in $S$, and then the $S$ value practically does not change. The $S$ parameter in lignite does not experience drastic change but shows a smooth decrease until the samples reach complete failure.

Ultrasonic wave attenuation in rocks is caused by multiple factors. On the micro level, scattering processes are strongly dependent on grain (pore) sizes (Jackson et al. 2002). On a larger scale, wave reflections on crack surfaces should be taken into account. In this case, the attenuation is affected by the ratio of the mechanical properties of the rock and the crack filler material (Mashinskii 2009). The strongest attenuation is observed on cracks, the dimensions of which are comparable with the wavelength of the used ultrasonic pulses. In our study we use broadband transducers, so wavelength ranges from 1 to $10 \mathrm{~mm}$. The main difference between the attenuation of longitudinal and transverse waves lies in the different mechanisms of signal reflection at the crack boundaries. Longitudinal waves can pass through cracks filled with liquid or gas, experiencing only partial reflection. Shear waves (dependent on the shear modulus of elasticity $G$ ) cannot propagate in gas or fluid and are reflected back at the crack boundary. In our study, predominantly air-filled crack formation should be expected (the samples are not water saturated and are not compressed by any external mechanical force). Therefore, a significant number of newly formed cracks act as shear wave propagation "blockers" affecting overall $A_{\mathrm{s}}$ attenuation, especially after the first F-T cycle. The magnitude of the crack opening is irrelevant in this case.

Studies examining $V_{\mathrm{p}}$ dependence on the number of F-T cycles have been carried out on various rocks (Yavuz 2011; Wang et al. 2018). They show an almost linear decline of $V_{\mathrm{p}}$ as the number of $\mathrm{F}-\mathrm{T}$ cycles grows. The authors attribute this change in $V_{\mathrm{p}}$ to the gradual development of pore space. Studies carried out on coal samples subjected to extreme F-T with liquid nitrogen report a nonlinear exponential decline in $V_{\mathrm{p}}$ (Qin et al. 2017a, b). Despite the exponential nature of the $V_{\mathrm{p}}$ change, a significant decrease in speed is still observed up to $10 \mathrm{~F}-\mathrm{T}$ cycles. In this case, differences between liquid $\mathrm{N}_{2}$ freezing and cold air freezing should be taken into account. Liquid nitrogen vaporizes when applied to the coal sample, increasing in volume up to 296 times. The high gas pressure acts as an additional tensile force that helps to spread open the cracks. Cold air cooling (used in the present study) occurs at a much lower rate. The main mechanisms of crack formation are explained by the $9 \%$ expansion of water when it turns into ice (Park et al. 2015). We cannot quantitatively compare the results of the present work with the results obtained by Qin et al. due to different types of coals and operating temperatures. However, qualitatively, even with a weaker thermal impact, a sharper change in the acoustic characteristics of coal is observed. This can be explained by the formation of multiple almost-closed cracks after the first FT cycle. Such cracks cannot be detected using $V_{\mathrm{p}}$ but lead to a significant decline in $A_{\mathrm{s}}$.

To characterize the propensity of coal fracturing under the influence of cyclic freezing-thawing, the coefficient of cryodesintegration $k_{\text {c.d. }}$ can be used as

$k_{\text {c.d. }}=\frac{S^{*}}{S^{0}}$,

where $S^{*}$ is the area of the polar diagram on the cycle after which the $S$ parameter stops changing and $S^{0}$ is the area of the polar diagram at the zero cycle.

The coefficient $k_{\text {c.d. }}$ varies in a range from 0 to 1 , with 1 indicating an absolute lack of tendency toward cryodesintegration and 0 indicating a strong tendency toward cryodesintegration. For the ratio between \#3 and \#0 cycles $k_{\text {c.d. }}$, the average values for anthracite, lignite and hard coal are $0.434,0.684$ and 0.674 , respectively. This shows that the densest and strongest coals are the most prone to destructive cryoimpacts under conditions of constant humidity levels.

Coal is known for its anisotropic mechanical properties. This anisotropy is explained by the conditions of coal formation. Dong (2008) showed that anisotropy can be related to porosity but is mainly caused by cracks. Natural anisotropy in the studied coals is clearly manifested in the zero F-T cycle (Figs. 4, 6). The initial values of averaged $K_{\mathrm{a}}$ for anthracite, hard coal and lignite are $1.77,1.62$, and 1.64 , respectively. The decrease in the $K_{\mathrm{a}}$ coefficient is manifested approximately equally for all types of studied coals, reaching minimum values after 3-6 cycles. The obtained results largely correspond to recent studies in which coal samples were subjected to changing internal gas pressure (Wang et al. 2019). In this case, an increase in the internal gas pressure in coals led to a decrease in the shear 
Table 2 The averaged results of the coal sample study

\begin{tabular}{llllll}
\hline Coal type & $\begin{array}{l}\text { Uniaxial strength } \\
(\mathrm{MPa})\end{array}$ & $K_{\mathrm{c.d}}$. & $\begin{array}{l}K_{\mathrm{a}} \text { at \#0 F-T } \\
\text { cycle }\end{array}$ & $\begin{array}{l}\text { Significant } K_{\mathrm{a}} \text { change up to:, F-T } \\
\text { cycle \# }\end{array}$ & Spectrum analysis features \\
\hline $\begin{array}{l}\text { Anthracite (group } \\
\text { A) }\end{array}$ & 22.0 & 0.434 & 1.77 & 3 & $f_{\text {max }}$ drops sharply after \#1 F-T \\
cycle & $f_{\text {max }}$ changes insignificantly \\
$\begin{array}{l}\text { Lignite (group L) } \\
\text { Hard coal (group }\end{array}$ & 12.0 & 0.684 & 1.62 & 3 & $f_{\text {max }}$ changes insignificantly \\
H) & 15.2 & 0.674 & 1.64 & 6 & \\
\hline
\end{tabular}

wave anisotropy. It appears that an increase in internal pressure (as well as low-magnitude cyclic F-T) leads to the formation of cracks uniformly and randomly distributed throughout the sample. This leads to a decrease in the role of natural anisotropy.

Spectral analysis of ultrasonic signals can provide additional information about the nature of crack formation. Thus, Wang et al. attempted to analyze the spectra of the longitudinal wave that passed through red sandstone samples subjected to cyclic cryothermal impacts (Wang et al. 2017). It was found that F-T leads to a gradual increase in the amplitudes of the low-frequency region of the spectrum. Simultaneously, a decrease in the amplitudes of the high-frequency region was discovered. Significant changes were observed after 10 freeze-thaw cycles. Similar regularities can be seen in the studied coals. The most significant change in the spectral composition of the S-waves appears after the first F-T cycle in the anthracite samples (Fig. 7a). In this case, the frequency of the spectrum maximum $f_{\max }$ declines sharply from $600 \mathrm{kHz}$ to $100 \mathrm{kHz}$. With further cycles, $f_{\max }$ undergoes minor changes. This can be explained by the formation of new cracks in the plane orthogonal to the $\mathrm{S}$-wave polarization. The high sensitivity of the shear wave to such cracks causes a sharper decline in $f_{\max }$ compared to longitudinal waves. No significant change in the spectral composition of S-waves is observed in more disturbed samples of lignite and hard coal. Initially, low $f_{\text {max }}$, which varies from 200 to $300 \mathrm{kHz}$ for both types of coals, should be noted. S-wave emission was performed by broadband transducers with a central frequency of $600 \mathrm{kHz}$. The "loss" of a significant part of the signal high frequencies indicates the presence of cracks in the samples located orthogonally to the anisotropy axis, as well as a general high level of initial disturbance.

Indirect analysis of the spectrum width based on the $\tau_{\mathrm{k}}$ estimation confirms the above conclusions. Significant changes in $\tau_{\mathrm{k}}$ are observed only in the anthracite samples. The increase in $\tau_{\mathrm{k}}$ corresponds to spectrum narrowing. It should be noted, however, that a smoother growth of $\tau_{\mathrm{k}}$ lags behind the sharp fall of $f_{\max }$.
The averaged results for all tested coal samples can be found in Table 2.

\section{Conclusions}

The acoustic properties of coal change under the influence of cyclic F-T operations. The authors investigated the patterns of polarized shear wave propagation in coal samples under cyclic F-T and came to the following conclusions:

(1) The high sensitivity of the $A_{\mathrm{s}}$ parameter to the formation of cracks with a small opening was shown. The greatest attenuation of shear waves with increasing F-T cycle number was observed in the anthracite samples. This was manifested to a lesser extent for hard coal samples. The smallest increase in attenuation was observed in lignite. Thus, an inverse correlation is observed between the initial strength of coal and its tendency to form cracks under the influence of low-magnitude freeze-thaw cycles.

(2) The greatest impact on the damage development in high-rank coals was established during the first freeze-thaw cycle.

(3) The initial anisotropy for all studied coal types was obtained using polarized shear waves. The anisotropy coefficients $K_{\mathrm{a}}$ for anthracite, lignite and hard coal were $1.77,1.62$ and 1.64 , respectively. As the F-T cycle number grew, the anisotropy coefficients decreased, reaching a minimum after 3-6 cycles.

(4) Spectral analysis of the recorded signals also confirmed intense crack formation in the anthracite samples after the first freeze-thaw cycle.

The formation of cracks (even with a small opening) in coal under the influence of cyclic freezing-thawing can lead to a decrease in its mechanical (decrease in strength) and consumer (oxidation level increase and calorific value decrease) properties. The data obtained from these studies form the basis for the development of new approaches to 
preserve coal during its storage and transportation under severe natural and climatic conditions.

Acknowledgements This research was funded by Russian Foundation for Basic Research, grant number 18-05-70002.

Author contributions Conceptualization, S.E. and V.S.; methodology, P.N.; software, P.N.; validation, P.N., S.E. and P.A.; formal analysis, V.S. and S.E.; investigation, P.N. and P.A.; resources, P.N.; data curation, V.S.; writing — original draft preparation, P.N.; writing-review and editing, S.E.; visualization, P.N.; supervision, S.E.; project administration, V.S.; funding acquisition, S.E. All authors have read and agreed to the published version of the manuscript.

\section{Compliance with ethical standards}

Conflict of interest The authors declare no conflict of interest.

Open Access This article is licensed under a Creative Commons Attribution 4.0 International License, which permits use, sharing, adaptation, distribution and reproduction in any medium or format, as long as you give appropriate credit to the original author(s) and the source, provide a link to the Creative Commons licence, and indicate if changes were made. The images or other third party material in this article are included in the article's Creative Commons licence, unless indicated otherwise in a credit line to the material. If material is not included in the article's Creative Commons licence and your intended use is not permitted by statutory regulation or exceeds the permitted use, you will need to obtain permission directly from the copyright holder. To view a copy of this licence, visit http://creativecommons. org/licenses/by/4.0/.

\section{References}

Aoki K, Hibiya K, Yoshida T (1990) Storage of refrigerated liquefied gases in rock caverns: characteristics of rock under very low temperatures. Tunn Undergr Space Technol 5(4):319-325. https://doi.org/10.1016/0886-7798(90)90126-5

Cai C, Li G, Huang Z, Shen Z, Tian S, Wei J (2014) Experimental study of the effect of liquid nitrogen cooling on rock pore structure. J Nat Gas Sci Eng 21(11):507-517. https://doi.org/10. 1016/j.jngse.2014.08.026

Cai C, Li G, Huang Z, Tian S, Shen Z, Fu X (2015) Experiment of coal damage due to supercooling with liquid nitrogen. J Nat Gas Sci Eng 22:42-48. https://doi.org/10.1016/j.jngse.2014.11.016

Cai C, Gao F, Li G, Huang Z, Hou P (2016) Evaluation of coal damage and cracking characteristics due to liquid nitrogen cooling on the basis of the energy evolution laws. J Nat Gas Sci Eng 29:30-36. https://doi.org/10.1016/j.jngse.2015.12.041

Cha M, Cho G-C, Santamarina JC (2009) Long-wavelength P-wave and $\mathrm{S}$-wave propagation in jointed rock masses. Geophysics 74(5):E205-E214. https://doi.org/10.1190/1.3196240

Deng J, Xiao Y, Li Q, Lu J, Wen H (2015) Experimental studies of spontaneous combustion and anaerobic cooling of coal. Fuel 157:261-269. https://doi.org/10.1016/j.fuel.2015.04.063

Dong SH (2008) Test on elastic anisotropic coefficients of gas coal. Acta Geophys Sin 51(3):947-952

Dwivedi RD, Soni AK, Goel RK, Dube AK (2000) Fracture toughness of rocks under sub-zero temperature conditions. Int J Rock Mech Min Sci 37(8):1267-1275. https://doi.org/10.1016/ S1365-1609(00)00051-4

Epshtein SA, Kossovich EL, Gavrilova DI, Agarkov KV (2019a) Effects of cyclic freeze-thawing of coals on their ability to oxidize. Gornyi Zhurnal 7:71-76. https://doi.org/10.17580/gzh. 2019.07.04

Epshtein SA, Nikitina IM, Agarkov KV, Nesterova VG, Minaev VI (2019b) Effects of cyclic freezing and thawing on coals quality indices. Min Inf Anal Bull 6:5-18. https://doi.org/10.25018/ 0236-1493-2019-06-0-5-18

Finnie I, Cooper GA, Berlie J (1979) Fracture propagation in rock by transient cooling. Int J Rock Mech Min Sci Geomech Abstr 16(1):11-21. https://doi.org/10.1016/0148-9062(79)90771-X

Gorbatsevich FF (1987) Physical principles and instruments for the acoustic polarization method of determining elastic anisotropy in rock samples. Geophys J Roy Astron Soc 91(2):493-500. https:// doi.org/10.1111/j.1365-246X.1987.tb05241.x

Gorbatsevich FF (2003) Acoustopolariscopy: a new direction in investigation of anisotropic heterogeneous media. Acta Acust (Stuttgart) 89:122-123

Jackson I, Fitz Gerald JD, Faul UH, Tan BH (2002) Grain-sizesensitive seismic wave attenuation in polycrystalline olivine. J Geophys Res Solid Earth 107(12):5-1-5-16

Kossovich EL, Borodich FM, Bull SJ, Epshtein SA (2016) Substrate effects and evaluation of elastic moduli of components of inhomogeneous films by nanoindentation. Thin Solid Films 619:112-119. https://doi.org/10.1016/j.tsf.2016.11.018

Kossovich E, Epshtein S, Dobryakova N, Minin M, Gavrilova D (2018) Mechanical properties of thin films of coals by nanoindentation. In: Karev V, Klimov D, Pokazeev K (eds) Springer geology. Springer, Cham, pp 45-50. https://doi.org/10.1007/9783-319-77788-7_6

Kundu T (2019) Mechanics of elastic waves and ultrasonic nondestructive evaluation. CRC Press, Boca Raton

Lin J, Ren T, Wang G, Nemcik J (2018) Simulation investigation of N2-injection enhanced gas drainage: model development and identification of critical parameters. J Nat Gas Sci Eng 55:30-41. https://doi.org/10.1016/j.jngse.2018.04.016

Liu SQ, Sang SX, Liu HH, Zhu QP (2015) Growth characteristics and genetic types of pores and fractures in a high-rank coal reservoir of the southern Qinshui basin. Ore Geol Rev 64(1):140-151

Mashinskii EI (2009) Strain amplitude-dependent attenuation of P and $S$ waves in dry and water-saturated sandstone under confining pressure. Russ Geol Geophys 50(8):734-738. https://doi.org/10. 1016/j.rgg.2008.12.013

Nicholson DT, Nicholson FH (2000) Physical deterioration of sedimentary rocks subjected to experimental freeze-thaw weathering. Earth Surf Proc Land 25(12):1295-1307. https://doi.org/ 10.1002/1096-9837(200011)25:12\%3c1295:AID-ESP138\%3e3. $0 . \mathrm{CO} ; 2-\mathrm{E}$

Novikov EA, Shkuratnik VL, Zaytsev MG, Oshkin RO (2018) Changes in properties and state of coal exposed to freeze-thaw weathering: evidence from thermally induced acoustic emission. Earth's Cryosphere 22(4):76-85. https://doi.org/10.21782/ KZ1560-7496-2018-4(76-85)

Pan J, Meng Z, Hou Q, Ju Y, Cao Y (2013) Coal strength and young's modulus related to coal rank, compressional velocity and maceral composition. J Struct Geol 54:129-135. https://doi.org/ 10.1016/j.jsg.2013.07.008

Park J, Hyun C-U, Park H-D (2015) Changes in microstructure and physical properties of rocks caused by artificial freeze-thaw action. Bull Eng Geol Environ Bull Eng Geol Environ 74(2):555-565. https://doi.org/10.1007/s10064-014-0630-8

Qin L, Zhai C, Liu S, Xu J, Tang Z, Yu G (2016) Failure mechanism of coal after cryogenic freezing with cyclic liquid nitrogen and its influences on coalbed methane exploitation. Energy Fuels 30(10):8567-8578. https://doi.org/10.1021/acs.energyfuels. $6 \mathrm{~b} 01576$

Qin L, Zhai C, Liu S, Xu J (2017a) Factors controlling the mechanical properties degradation and permeability of coal subjected to 
liquid nitrogen freeze-thaw. Sci Rep 7(1):3675. https://doi.org/ 10.1038/s41598-017-04019-7

Qin L, Zhai C, Liu S, Xu J, Yu G, Sun Y (2017b) Changes in the petrophysical properties of coal subjected to liquid nitrogen freeze-thaw. A nuclear magnetic resonance investigation. Fuel 194:102-114. https://doi.org/10.1016/j.fuel.2017.01.005

Qin L, Zhai C, Liu S, Xu J (2018) Mechanical behavior and fracture spatial propagation of coal injected with liquid nitrogen under triaxial stress applied for coalbed methane recovery. Eng Geol 233:1-10. https://doi.org/10.1016/j.enggeo.2017.11.019

Remy JM, Bellanger M, Homand-Etienne F (1994) Laboratory velocities and attenuation of $\mathrm{P}$-waves in limestones during freeze-thaw cycles. Geophysics 59(2):245-251. https://doi.org/ $10.1190 / 1.1443586$

Santos CA, Urdaneta V, Jaimes G, Trujillo L (2010) Ultrasonic spectral and complexity measurements on brine and oil saturated Rocks. Rock Mech Rock Eng 43(3):351-359. https://doi.org/10. 1007/s00603-009-0047-z

Shamina OG, Palenov AM (2000) Elastic wave spectra and fracture. Izvestiya Phys Solid Earth 36(3):196-203

Shkuratnik VL, Nikolenko PV, Koshelev AE (2016) Stress dependence of elastic p-wave velocity and amplitude in coal specimens under varied loading conditions. J Min Sci 52(5):873-877. https://doi.org/10.1134/S1062739116041322

Shkuratnik VL, Nikolenko PV, Anufrenkova PS (2020) About features of ultrasonic measurements in coal samples using shear elastic waves. Min Inf Anal Bull 4:117-126. https://doi.org/10. 25018/0236-1493-2020-4-0-117-126

Sun Y, Zhai C, Qin L, Xu J, Yu G (2018) Coal pore characteristics at different freezing temperatures under conditions of freezingthawing cycles. Environ Earth Sci 77(13):525. https://doi.org/10. 1007/s12665-018-7693-y
Wang P, Xu J, Fang X, Wang P, Zheng G, Wen M (2017) Ultrasonic time-frequency method to evaluate the deterioration properties of rock suffered from freeze-thaw weathering. Cold Reg Sci Technol 143:13-22. https://doi.org/10.1016/j.coldregions.2017. 07.002

Wang L, Li N, Qi J, Tian Y, Xu S (2018) Study on changes in integrity decay of sandstone subjected to freeze-thaw cycling. In: $\mathrm{Wu} \mathrm{W}, \mathrm{Yu}$ HS (eds) Springer series in geomechanics and geoengineering. Springer, Cham, pp 1420-1423. https://doi.org/ 10.1007/978-3-319-97115-5_114

Wang B, Hao J, Li S, Zhou F, Zhang Z, Zhan H, Sun H (2019) Experimental study on the effect of gas pressure on ultrasonic velocity and anisotropy of anthracite. Geofluids 2019:3183816. https://doi.org/10.1155/2019/3183816

Winkler EM (1968) Frost damage to stone and concrete: geological considerations. Eng Geol 2(5):315-323. https://doi.org/10.1016/ 0013-7952(68)90010-0

Yavuz H (2011) Effect of freeze-thaw and thermal shock weathering on the physical and mechanical properties of an andesite stone. Bull Eng Geol Environ 70(2):187-192. https://doi.org/10.1007/ s10064-010-0302-2

Yu Y, Liang W, Hu Y, Meng Q (2012) Study of micro-pores development in lean coal with temperature. Int J Rock Mech Min Sci 51:91-96. https://doi.org/10.1016/j.ijrmms.2012.01.010

Zhai C, Wu S, Liu S, Qin L, Xu J (2017) Experimental study on coal pore structure deterioration under freeze-thaw cycles. Environ Earth Sci 76(15):507. https://doi.org/10.1007/s12665-017-68299

Zhang G, Ranjith PG, Perera MSA, Lu Y, Choi X (2019) Quantitative analysis of micro-structural changes in a bituminous coal after exposure to supercritical $\mathrm{CO}_{2}$ and water. Nat Resour Res 28(4):1639-1660. https://doi.org/10.1007/s11053-019-09463-y 